\title{
Quantitative scintigraphy in discriminating sacroiliac joint physiological and pathological uptake
}

\author{
Shaimaa F. Abdelhai', Heba M. Abdelhamed', Abeer M. El-Shafey ${ }^{2}$ and Rania M. Almolla ${ }^{3 *}$
}

\begin{abstract}
Background: Bone scintigraphy is a highly sensitive diagnostic nuclear medicine imaging technique that uses a radiotracer to evaluate the distribution of active bone formation in the skeleton related to malignant and benign diseases, as well as physiological processes. Subjective increase of the radioactivity at the sacroiliac joint in cancer patients could indicate physiological, metastatic, or inflammatory (sacroiliitis) cause. In this single-center study, we aimed to settle the normal sacroiliac index (SII) in males and females and if it differs from side to other, as a more accurate quantitative method than qualitative one, and assess its validity in discriminating the cause in pathological increase.

Results: Sacroiliac index can differentiate physiological uptake at the SIJ from pathological uptake with a highly significant value $(P<0.001)$. Using SIl at a cutoff value 1.17 had $100 \%$ sensitivity and specificity in differentiating between the two conditions. The normal SII in our institute ranged from 0.9 to 1.14 with no significant difference between right and left SIJs. The mean SII was $1.33 \pm 0.11$ in patients with ankylosing spondylitis (AS) and $1.38 \pm 0.1$ in metastatic cases with no significant difference in SIl between the two diseased groups $(P=0.49$ ).

Conclusion: Bone scintigraphy is widely used in our institute and qualitative assessment of SIJ uptake is sometimes confusing. In this study, we assessed the normal SII range in physiological uptake and assessed a cutoff value (which is lower than other races) above which any increase in SIJ uptake is considered pathological. We could not confirm a cutoff value to discriminate between AS and metastatic affection of SIJ.
\end{abstract}

Keywords: Ankylosing spondylitis, Metastasis, Scintigraphy, Sacroiliac index, Sacroiliac joint

\section{Background}

Bone metastasis is a debilitating and incurable disease. Disseminated tumor cells (DTCs) from various common malignancies such as breast, prostate, lung, and kidney cancers or myeloma are uniquely primed to subvert these endogenous bone stromal elements to grow into pathological osteolytic or osteoblastic lesions [1]. Skeletal-related events that are due to bone metastases can include pain, pathological fracture, hypercalcemia, and spinal cord compression [2].

\footnotetext{
* Correspondence: Ranyaalmola@gmail.com

${ }^{3}$ Department of Radiodiagnosis, Faculty of Medicine, Zagazig University, Zagazig, Egypt

Full list of author information is available at the end of the article
}

The life span of patients with the metastatic bone disease is limited; thus, the goal of management should center on returning as much function as possible and as rapidly as possible [3]. Diagnosis of bone metastases can be done by different methods; 99mTC MDP bone scan is widely regarded as the most cost-effective and available whole-body screening for bone metastases, but it is subjective and not specific [4].

Sacroiliitis is a common manifestation of spondyloarthropathies which are mostly accepted as a spectrum of different disease types originating from undifferentiated spondyloarthropathy to well-established ankylosing spondylitis [5]. Ankylosing spondylitis (AS) is a complex 
potentially debilitating disease [6]. Ankylosing spondylitis commonly starts in the second or third decade of life $[7,8]$.

Bone scintigraphy is a highly sensitive diagnostic nuclear medicine imaging technique that uses a radiotracer to evaluate the distribution of active bone formation in the skeleton related to malignant and benign disease, as well as, physiological processes [9]. The European Association of Nuclear Medicine (EANM) has approved using bone scintigraphy to diagnose spondyloarthropathies and related disorders such as ankylosing spondylitis in its guidelines [10-12].

Since there is physiological uptake in the sacroiliac joints, it is hampered by this drawback as a diagnostic method. The addition of quantitative methods (comparing the sacroiliac joint activity with background activity like sacrum) to bone scintigraphy has revealed an increase in the sensitivity and has pointed the results in agreement with clinical findings [13].

So increased radiotracer uptake at the sacroiliac joint could be due to the physiological process, metastasis, or sacroiliitis.

Many studies proved that race affects the SII value [6]. Unfortunately, we do not have our index for Egyptians, so we aimed to determine the normal SII in our institute, assess its validity in discriminating physiological from pathological SIJ uptake at a certain cutoff value, and trying to differentiate the cause of increased SIJ uptake in cancer patients.

\section{Methods}

A prospective study was carried out in the nuclear medicine unit and radiodiagnosis department at our institution from June 2018 to February 2019.

\section{Subjects}

Our patients were classified into 3 groups:

Group I: twenty-five males and 15 females (age ranged from 23 to 55 years, mean $35 \pm 11.8$ ) were included. All of them were cancer patient underwent bone scintigraphy and proved clinically and radiologically free from any SIJ affection. None of those subjects had any findings or symptoms such as back pain or joint stiffness that suggests sacroiliitis, besides none, had a systemic disease like systemic lupus erythematosus (SLE) or diabetes mellitus (DM). All our control subjects underwent routine bone scintigraphy and revealed no abnormality followed by X-ray radiography of both sacroiliac joints.

Group II: twenty patients, 14 males and 6 females (age ranged from 23 to 37 years, mean $32 \pm 3.5$ ) were included. They were sent from the rheumatology department suffering from ankylosing spondylitis (AS), diagnosed according to the 1984 modified New York criteria for classification of AS, which requires at least 1 clinical manifestation and at least 1 radiographic parameter [14]. Clinical manifestations include $\geq 3$ months of inflammatory back pain that improves with exercise and exacerbated by rest, limitation of lumbar motion in both frontal and sagittal planes, and limitation of chest expansion compared to the normative population. Assessment of ankylosing spondylitis activity was done according to the bath ankylosing spondylitis disease activity index (BASDAI) [15]. Patients with sacroiliitis associated with either psoriatic skin disease or colonoscopy-proven inflammatory bowel disease were excluded from the study.

Group (III): twenty-two patients, 14 females and 8 males (age ranged from 30 to 55 years, mean $38 \pm 8.8$ ) were included. They had different types of carcinomas (12 breast, 4 prostate, and 6 colorectal) and sent to our unit for metastatic follow-up. We included patients with abnormal radiotracer uptake in the sacroiliac region at a bone scan and proved to be osseous deposits by X-ray in 3 patients or MSCT in the rest of the patients (19 patients).

All subjects in the three groups were subjected to a full clinical examination of the locomotor system with stress on sacroiliac joint examination by the following tests: sacral compression test; pelvic distraction test; pelvic compression test; flexion, abduction, and external rotation (FABER) test; and Ganslen's test [16].

\section{Methods}

\section{Laboratory investigations}

- Erythrocyte sedimentation rate (ESR), C-reactive protein (CRP), complete blood count (CBC), liver, and kidney function tests for all cases

- HLA-B27 testing at the time of diagnosis of AS

\section{$X$-ray radiography}

- Was done for all cases in groups I and II and for 3 cases in group III. Anteroposterior (AP) plain radiography of the pelvis and Ferguson's view of the right (RT) and left (LT) SI joints were done.

- In group II, positive radiographic parameters include $\geq$ grade 2 sacroiliitis bilaterally or grades 3 or 4 sacroiliitis unilaterally [14].

- In group III, any lytic or sclerotic lesion at SIJ was diagnosed as a metastatic deposit.

\section{Pelvic CT}

CT was done for all patients in group III (except 3 cases had claustrophobia but their plain radiographic findings were sufficient). Pelvic multislice CT (MSCT) scans were done (using 128 multislice ingenuity CT, Philips Medical Systems, Netherland) within a single breath-hold from the iliac crest to the ischial tuberosities with $5-\mathrm{mm}$ beam 
collimation and 5-mm/s table speed: $\mathrm{mAs}, 250-300$ and $\mathrm{KV}, 120-140$. The images were reconstructed using bone windows in coronal and sagittal planes with 1.5 $\mathrm{mm}$ thickness and 1.5-mm intervals (WW 2000, WL 800 ). Images were interpreted by two experienced radiologists and any lytic bony lesion in the sacrum or the iliac bone was reported as bone deposit (bilateral involvement, 14 cases. LT sided in 5 cases RT sided and 3 cases).

\section{Bone scintigraphy}

A whole-body skeletal survey by scintigraphy using 99mTc-methylene diphosphonate (MDP) was done for the three groups (82 patients).

Patient preparation Patients were informed about the appropriate preparation instructions and radiation protection measures and all married females within the child-bearing period did a pregnancy test before the study.

Imaging After $3 \mathrm{~h}$ of intravenous injection of $20 \mathrm{mCi}$ (740 MBq), ${ }^{99 m}$ Tc-MDP was given via a cannula, then we did anterior and posterior planner views of the entire skeleton (20\% energy window set at a peak of $140 \mathrm{keV}$ of ${ }^{99 \mathrm{~m}} \mathrm{Tc}$, using $256 \times 256$ matrix size, obtained with a dual-headed gamma camera equipped with low-energy high-resolution collimators (General Electric camera, USA)).

Calculation of the SII A rectangular region of interest (ROI) was drawn covering the entire left sacroiliac joint posteriorly and a similar ROI over the right sacroiliac joint was copied. A third ROI was drawn over the center of the sacrum which represented background activity. The average counts were estimated for each ROI to calculate the sacroiliac (SI) indices.

SII was calculated for each sacroiliac joint as follows:

Left sacroiliac index (LSI) = average LT.SI ROI count/ average sacrum ROI count.

Right sacroiliac index (RSI) $=$ average RT.SI ROI count/average sacrum ROI count.

\section{Statistical analysis}

Statistical analysis was performed using the Statistical Package for the Social Sciences (SPSS version 14.0 software by Robert H. Carver and Jane Gradwohl Nash). The comparison between the studied groups in sex was done by chi-square test and in age by ANOVA test. The comparison between SII in both sides of the sacroiliac joint among normal individuals was done by using the paired Student's $t$ test, while comparisons between the SII values between the normal group and the diseased groups as well as between the two diseased groups were done by using the independent samples $t$ test.

Results were presented as number and percentage for qualitative data and mean \pm standard deviation (SD) and range for quantitative data. $P$ values less than 0.05 were considered to be significant and less than 0.01 were considered to be highly significant. Roc curve was used to calculate the SII cutoff between the normal and the two diseased groups.

\section{Results}

Our study included 82 subjects, 46 female and 36 males a long study period from June 2018 to February 2019. They are classified into three groups (Table 1).

Group I: forty normal individuals (80 sides) with no radiological signs of any sacroiliac joint disease in both sides (Fig. 1, S1). Group II: twenty patients with clinically, laboratory, and radiologically proved sacroiliac ankylosing spondylitis (35 sides, 15 bilateral and 5 unilateral) (Figs. 2, 3 and S2). Group III: twenty-two patients with radiologically proved sacroiliac joint metastasis (36 sides, 14 bilateral and 8 unilateral) (Figs. 4, 5, and S3). All were subjected to bone scintigraphy and the values of the sacroiliac index (SII) in each SII were calculated and reported.

In our control group (group I), the value of SII was ranged from 0.91 to 1.13 , mean $1.04 \pm 0.09$ on the right side and ranged from 0.9 to 1.14 , mean $1.04 \pm 0.05$ on the left side. No statistically significant difference between the right and left sacroiliac joints, nor between females and males $(P$ value $>0.05)$ (Table 2$)$ (Fig. 1$)$.

The mean and the range of the SII in the other two groups were higher than that in the normal individual: in group II (range 1.2-1.5, mean $1.37 \pm 0.1$ ) and group III (range 1.2-1.6, mean $1.39 \pm 0.14$ ) (Table 3) (Figs. 2, 3,4 , and 5).

A highly statistically significant difference was found between the SII in group I and the other two pathological groups ( $P$ value $<0.001^{* * *}$ each) (Table 3$)$. However, no significant difference in SII between the two diseased groups $(P$ value $>0.05)$. Sacroiliac index at a cutoff value 1.17 had $100 \%$ sensitivity and specificity in differentiating between physiological and pathological SIJ uptake (Table 4).

\section{Discussion}

Bone scintigraphy is a highly sensitive diagnostic nuclear medicine imaging technique that uses a radiotracer to evaluate the distribution of active bone formation in the skeleton related to malignant and benign disease, as well as, physiological uptake [9]. The criterion for a positive diagnostic study is an increase of the activity accumulation in sacroiliac joints compared to sacrum activity as a background [13]. The addition of quantitative methods (comparing the sacroiliac joint activity with background 
Table 1 Significant difference between the three groups regarding gender, number of SIJs examined, and age

\begin{tabular}{|c|c|c|c|c|c|c|}
\hline Groups (side $N$ ) & Gender & Sides N (151) (\%) & $P\left(\right.$ chi-square test $\left.\left(x^{2}\right)\right)$ & Age (range) & Mean \pm SD & $P($ ANOVA test $(F))$ \\
\hline \multirow[t]{2}{*}{ Group I $(n=80)$} & Females & 50 side (33.1) & 0.07 & $23-55$ & $35 \pm 11.8$ & 0.14 \\
\hline & Males & 30 side (19.9) & & & & \\
\hline \multirow[t]{2}{*}{ Group II $(n=35)$} & Females & 11 side (7.3) & & $23-37$ & $32 \pm 3.5$ & \\
\hline & Males & 24 side (15.9) & & & & \\
\hline \multirow[t]{2}{*}{ Group III $(n=36)$} & Female & 24 side (15.9) & & $30-55$ & $38 \pm 8.8$ & \\
\hline & Males & 12 side $(7.9)$ & & & & \\
\hline
\end{tabular}

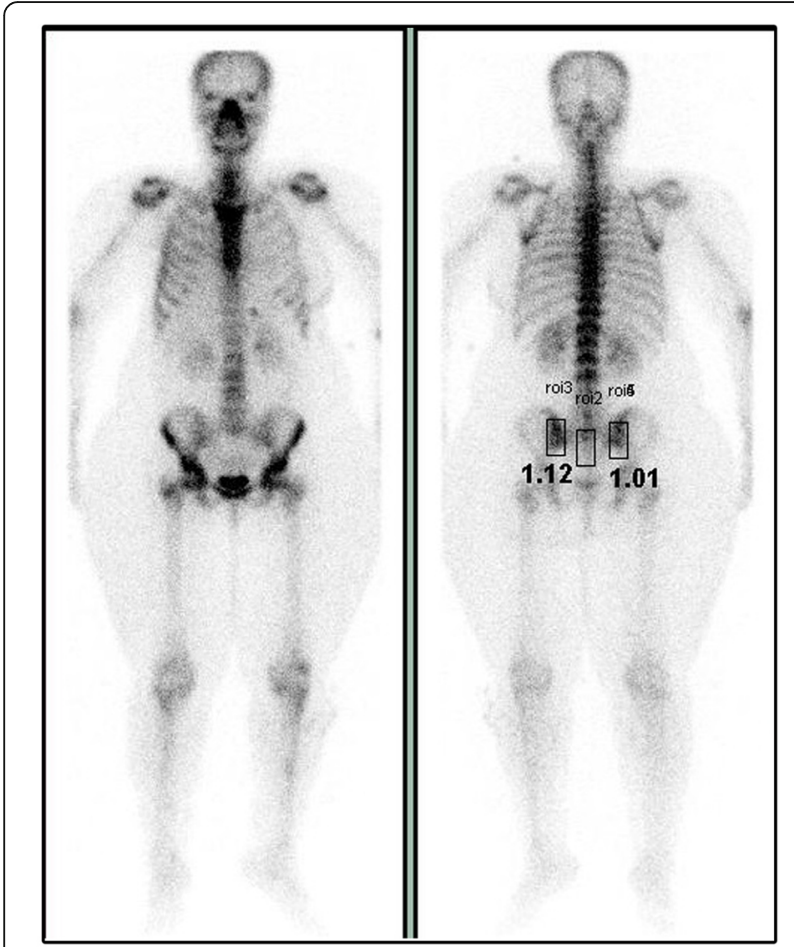

(A)

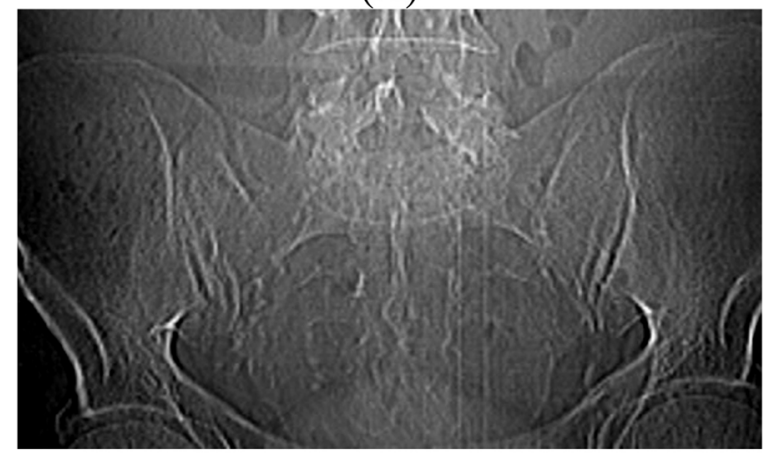

(B)

Fig. 1 Normal physiological uptake of both sacroiliac joints in 38 years old female. a Tc-99 m MDP whole-body bone scintigraphy (anterior and posterior views) shows right SII $=01.01$ and left SII $=$ 1.12. $\mathbf{b}$ X-ray radiography of sacroiliac joints (AP view) shows normal both sacroiliac joints

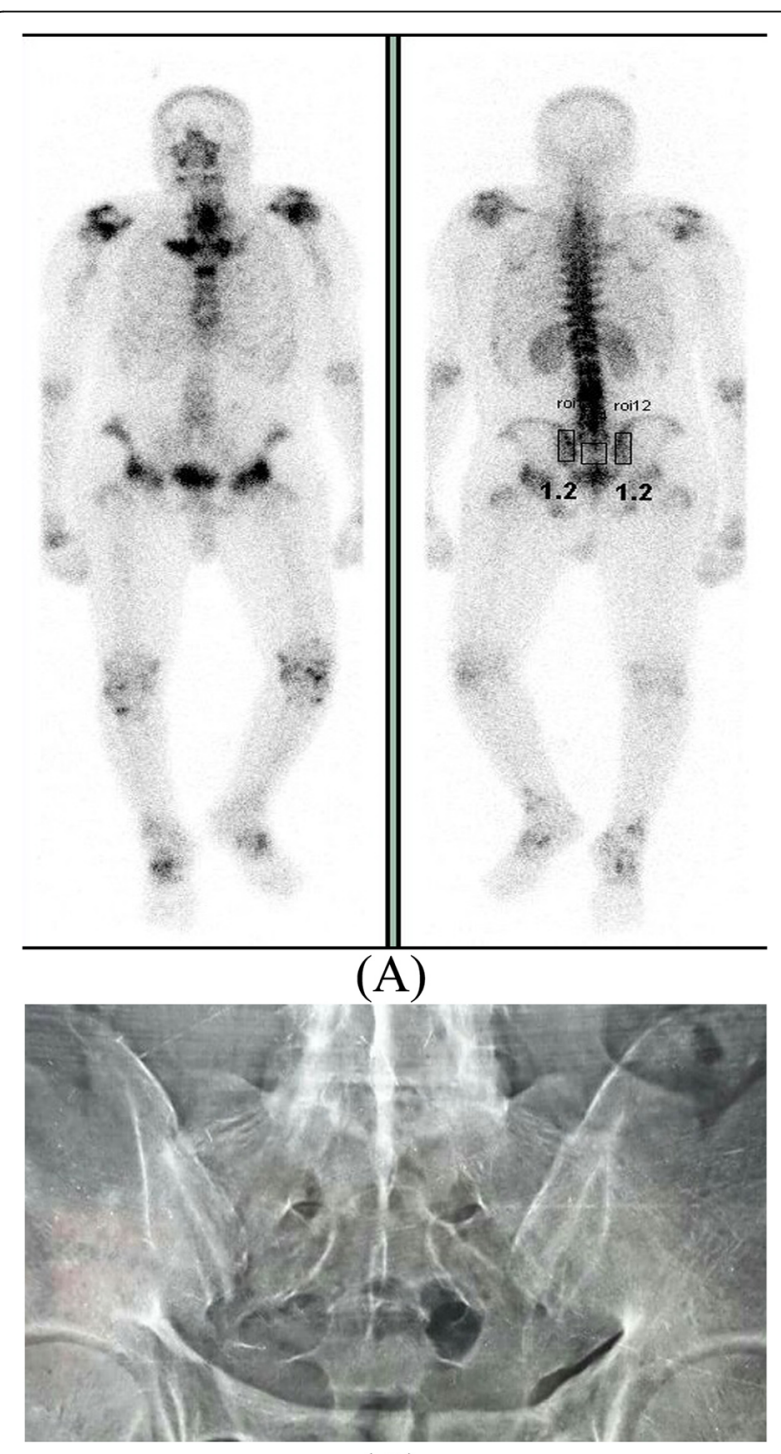

(B)

Fig. 2 Forty-eight years old male with ankylosing spondylitis. a Tc$99 \mathrm{~m}$ MDP whole-body bone scintigraphy (anterior and posterior views) shows increased uptake of both sacroiliac joints (right SII = 1.2, left SII =1.2). $\mathbf{b}$ X-ray radiography of sacroiliac joints (AP view) reveals sclerosis, irregularity, and narrowing of both sacroiliac joints 

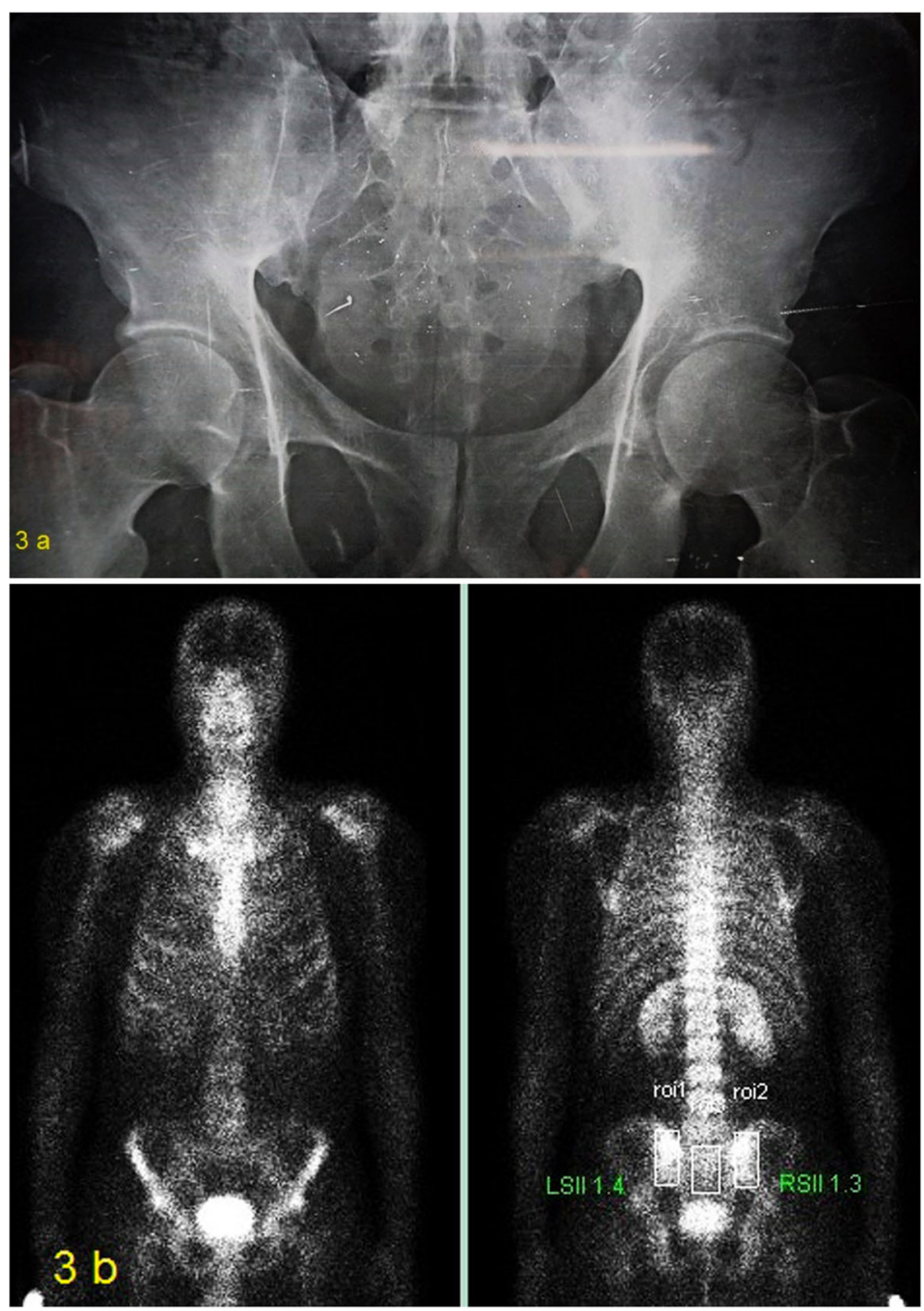

Fig. 3 Thirty-three years old male with ankylosing spondylitis. a X-ray radiography of sacroiliac joints (AP view) reveals sclerosis, irregularity, and narrowing of the RT SIJ and fused LT one. b Tc-99 m MDP whole-body bone scintigraphy (anterior and posterior views) shows increased uptake of both sacroiliac joints (right SII = 1.3, left SII = 1.4)

activity like sacrum) to bone scintigraphy has revealed an increase in the sensitivity of the bone scintigraphy [17].

Sieper et al. [6] stated that: "Since there is physiological uptake of Tc99MDP in the sacroiliac joints so, every institution should establish its own normal range." From this point, we did this research as the first trial in Egypt to assess the SII in our institute.

Bijaynath et al. [18] found that the overall SII ranged from 1.06 to 1.36 in the study population of 100 normal subjects encompassing all age groups. The values of SII differ at different age groups as follows: in patients aged 2-20 years, SII ranged from 1.22 to 1.36 . In patients aged 21-40 years, it ranged from 1.07 to 1.19 , and for patients aged 41-60 years, it ranged from 1.08 to 1.19 . In patients aged 61 years and older, SII values were slightly lower than in other groups and ranged from 1.06 to 1.13. In our study, we included close age ranges to avoid the influence of age on SII as a bias in our research. The age of our patients ranged from 23 to 55 years with overall SII range was 0.9-1.14 (mean $1.04 \pm 0.09$ ) and these values were in agreement with the aforementioned study [18].

In group I, we assessed the SII in both SIJ in each patient and found no significant difference between the two sides $(P>0.92)$. This was matching with many 


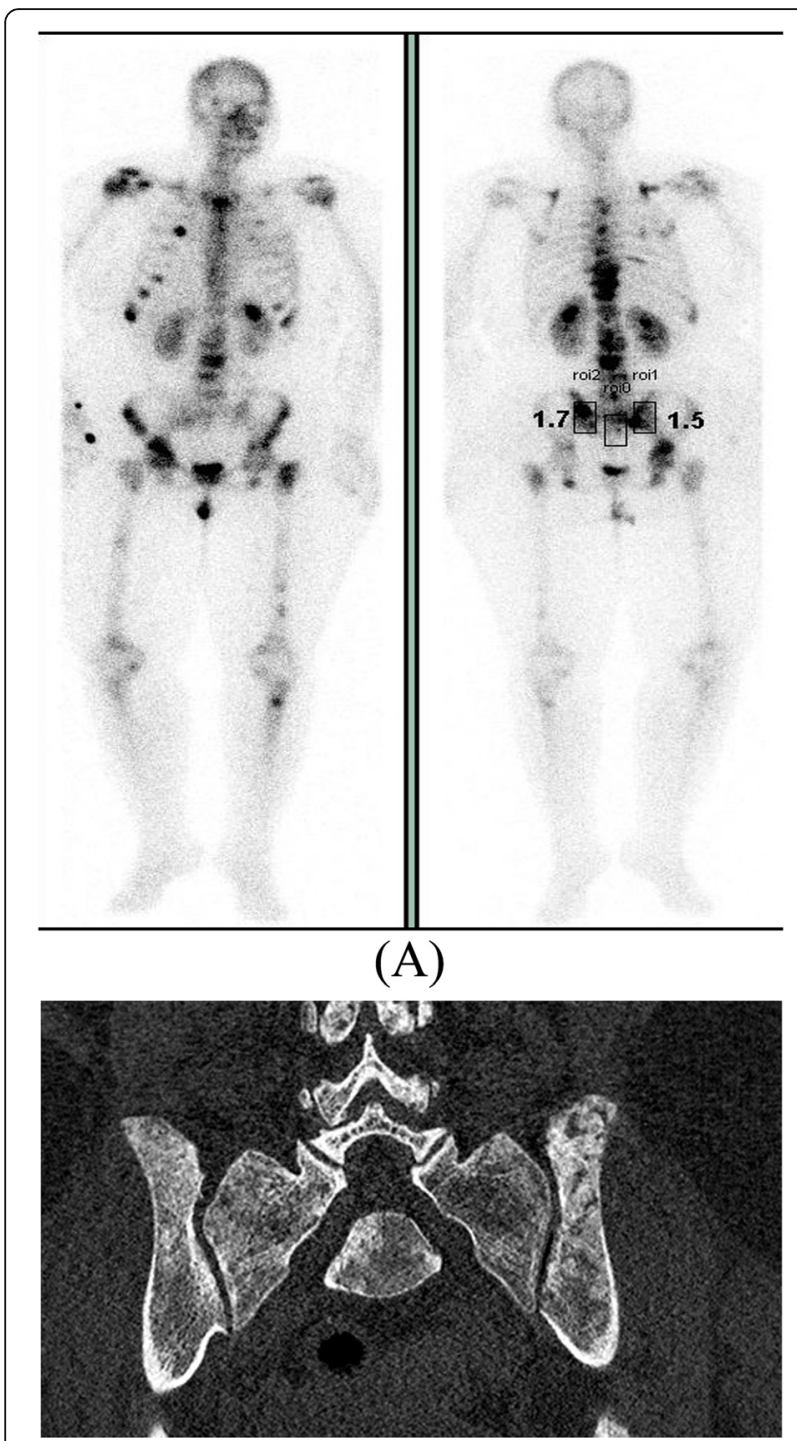

(B)

Fig. 4 Fifty-five years old female with metastatic cancer breast. a Tc$99 \mathrm{~m}$ MDP whole-body bone scintigraphy (anterior and posterior views) shows multiple regions of increased uptake including both sacroiliac joints (right $\mathrm{SII}=1.5$, left $\mathrm{SII}=1.7$ ). b Coronal MSCT (bone window) shows multiple mixed lytic and sclerotic bony deposits involving both sacroiliac joints

previous studies $[5,6]$ stating that there is no significant difference in SII between the right and the left SIJs with SII in the RT side $1.23 \pm 0.26$ vs. $1.25 \pm 0.25$ in the left side $(P$ value $>0.66$. $)[5]$.

Kacar et al. [17] compared the SII in healthy individuals (included 47 subjects) and sacroiliitis patients (13 cases) with also no significant difference in SII between the two sides of the sacroiliac joint in both healthy and diseased sides. However, they found a significant difference between males and females $(P<0.05)$ with higher SII in males and also a significant SII decrease in aged women. This may reflect the influence of a wide age range included in their study and explain also why we exclude extremities of age in our study.

In our results, we found that the mean SII in female was $1.03 \pm 0.08$ (at the right) and $1.04 \pm 0.09$ (at the left) and the mean SII in males was $1.04 \pm 0.09$ (at the right) and $1.04 \pm 0.09$ (at the left) with no significant difference regarding the gender. This was disagreeing with Vyas et al. [19] who found a significant difference between male and female with the SIIs in females ranged from 0.92 to 1.48 (right) and $0.88-1.32$ (left) vs. in male $0.87-$ 1.67 (right) and 0.82-1.62 (left); however, they disagree with us and a previous study [18] as they found that the age did not influence the SII.

We think that the different SII in normal subjects regarding the gender in our study and other studies $[17,19]$ may be attributed to the racial differences between different studied populations.

In a pediatric study [5], females had higher SII than males with a significant difference in SII when they used sacrum as a background reference in index calculation but when they repeated the index calculation using L1 vertebra as a background, they found no difference between the two genders. This may reflect influence of bone marrow composition upon radioactive materials' uptake. This highlights the importance of fixing the method of measuring the SII in each institute.

Davis et al. [20] found in their study on a family that has members with Crohn's disease and others with AS that, diagnosis of ankylosing spondylitis in the patient with Crohn's disease could not be confirmed owing to the absence of radiological change. However, quantitative sacroiliac scintigraphy confirmed the presence of inflammatory disease at the sacroiliac joints, with SII 1.79 at the LT side and 1.62 at the RT.

The range of SII among our patients with AS (group II) was $1.2-1.5$, mean $1.37 \pm 0.1$, with a highly significant difference with the first groups $(P<0.001)$. This is agreeing with Ozdogan et al. [21] who found that there was a significant difference between the control group and patients with ankylosing spondylitis. Also, they reported that the right SII in AS was $1.48 \pm 0.22$ vs. $1.29 \pm$ 0.17 for the control group and left SII was $1.47 \pm 0.20$ for the patient group vs. $1.32 \pm 0.18$ for the control group.

On the other hand, Kim et al. [22] stated that there is no significant difference in SII between the control group (SII $=1.10 \pm 0.21$ ) and patients with AS (SII = $1.12 \pm 0.17$ ) by planner bone scan; however, there was a significant difference $(P=0.014)$ when they used SPECT/CT. This reflects the high advantage of using SII 

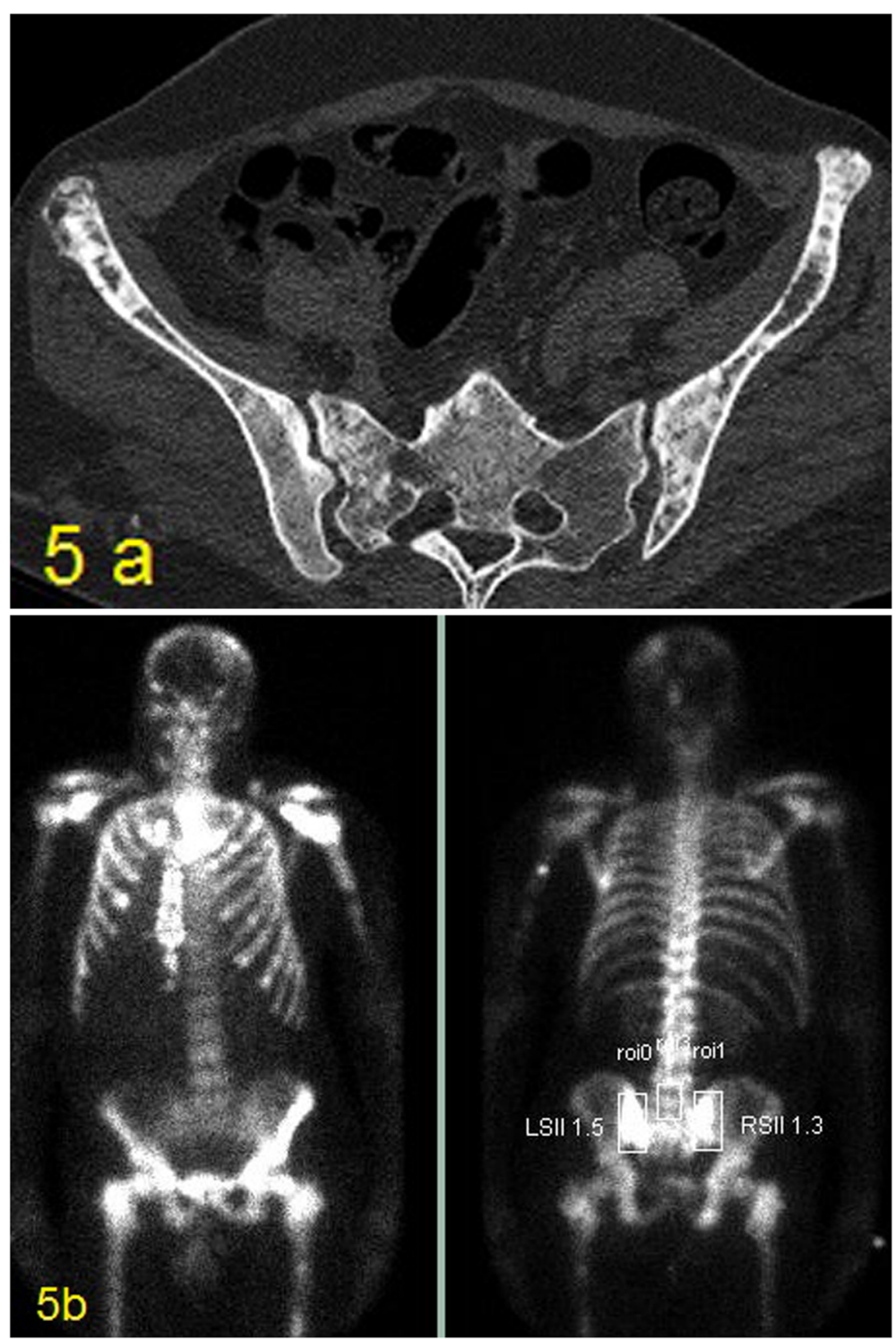

Fig. 5 Forty-five years old male with metastatic cancer prostate. a Axial MSCT (bone window) shows multiple mainly sclerotic bony deposits involving both sacroiliac joints. b Tc-99 m MDP whole-body bone scintigraphy (anterior and posterior views) shows multiple regions of increased uptake including both sacroiliac joints (right SII $=1.3$, left SII = 1.5)

Table 2 Range, mean, and SD of SII between female and male in group1

\begin{tabular}{|c|c|c|c|c|c|}
\hline \multirow[t]{2}{*}{ Group 1} & \multicolumn{2}{|l|}{ RT SII } & \multicolumn{2}{|l|}{ LT SII } & \multirow{2}{*}{$\begin{array}{l}P \\
\text { (paired } \\
t \text { test) }\end{array}$} \\
\hline & Range & Mean $\pm \mathrm{SD}$ & Range & Mean \pm SD & \\
\hline Female normal individuals $(n=25)$ & $0.9-1.12$ & $1.03 \pm 0.08$ & $0.9-1.13$ & $1.04 \pm 0.09$ & 0.68 \\
\hline Male normal individuals $(n=15)$ & $0.9-1.13$ & $1.04 \pm 0.09$ & $0.9-1.14$ & $1.04 \pm 0.09$ & 0.96 \\
\hline $\mathrm{P}$ (independent $t$ test) & 0.71 & & 0.94 & & \\
\hline
\end{tabular}

Non-significant $(P>0.05)$ 
Table 3 Range, mean, and SD of SII in the normal, ankylosing spondylitis, and metastatic cases

\begin{tabular}{llll}
\hline Group & Range of SII & Mean \pm SD & $P$ \\
\hline Group I & & & P1 (paired $t$ test) $=0.92$ \\
P2 (independent $t$ test) $=<0.001^{* *}$ \\
RT. SII $(n=40)$ & $0.91-1.13$ & $1.04 \pm 0.09$ & P3 (independent $t$ test) $=<0.001^{* *}$ \\
LT. SII $(n=40)$ & $0.9-1.14$ & $1.05 \pm 0.09$ & P4 (independent $t$ test) $=0.49$ \\
Overall SII $(n=80)$ & $0.9-1.14$ & $1.04 \pm 0.09$ & \\
Group II $(n=35)$ & $1.2-1.5$ & $1.37 \pm 0.1$ & $1.39 \pm 0.14$ \\
Group III $(n=36)$ & $1.2-1.6$ &
\end{tabular}

Non-significant $(P>0.05){ }^{* *}$ Highly significant $(P<0.01)$

P1, RT vs. LT in group I; P2, group I vs. group II; P3, group I vs. group III; P4, group II vs. group III

as a quantitative method, also avoids the proceeding for further coast imaging modalities.

Our third group included patients with increased uptake at one or both SIJs and proved to have SIJ deposits by MSCT bone window. The range of SII was 1.2-1.6, mean $1.39 \pm 0.14$. We found an overlap in SII among groups II and III with no significant difference between the two groups ( $P$ value was 0.1 ); it may be due to a small number of included cases, so more studies are needed to confirm the importance of this index.

Few studies tried to determine the cutoff value for SII $[20,22]$. In our study, the SII at a cutoff less than 1.17 was considered normal. However, a higher cutoff value (SII < 1.3) was reported by [20], also, another study used SPECT/CT, determined a cutoff at 1.50 to differentiate between normal and AS subjects [22]. This may reflect lower mean of SII in Egyptians than other races.

As we know bone scintigraphy is a routine investigation in follow-up of all cancer patients, so our research could be the beginning for further larger and wider studies to assess the SII by many institutes to settle a uniform index which could help in daily work.

The limitations of our study were the small number of included subjects as we limited the study to certain age groups to avoid the influence of age. Also, we used a manual method to calculate SII due to limited equipment and Gamma Camera software in our institute.

\section{Conclusion}

The sacroiliac index is a helpful, easy, and costless quantitative parameter to avoid the hesitation during the daily interpretation of SIJ radiotracer uptake which depends only on the qualitative method. In this study, we

Table 4 Validity of SII in differentiating physiological from pathological radioactivity at a cutoff value 1.17

\begin{tabular}{lllllllll}
\hline SII & AUC & $\mathrm{Cl}(95 \%)$ & Sen. & Spec. & PPV & NPV & Accuracy & $P$ \\
\hline$>1.17$ & 1 & $1-1$ & 100 & 100 & 100 & 100 & 100 & $<0.001^{* *}$ \\
\hline **Highly significant $(P<0.01)$ & & & & &
\end{tabular}

assessed the normal SII range in physiological uptake and established a cutoff value (which is lower than other races) above which any increase in SIJ uptake is considered pathological. We could not confirm a cutoff value to discriminate between AS and metastatic affection of SIJ. So, further studies upon this index are still mandatory to specify the cause of high SII.

\section{Supplementary information}

Supplementary information accompanies this paper at https://doi.org/10. 1186/s43055-020-00234-X.

Additional file 1: S1. Normal physiological uptake of both sacroiliac joints in 42 years old female (A) Tc-99m MDP whole-body bone scintigraphy ( Anterior and posterior views) shows Right SII=0.9 and Left $S I I=1$. S2. Thirty-two years old female has ankylosing spondylitis. Tc-99m MDP whole-body bone scintigraphy (Anterior and posterior views) shows increased uptake of both sacroiliac joints (Right $S \|=1.4$, Left $S \|=1.3$ ). S3. Fifty years old female has metastatic cancer breast. Tc-99m MDP wholebody bone scintigraphy (Anterior and posterior views) shows multiple regions of increased uptake including both sacroiliac joints (Right SII = 1.6, Left SII=1.4).)

\section{Abbreviations}

AS: Ankylosing spondylitis; BASDAl: Bath ankylosing spondylitis disease activity index; DTCs: Disseminated tumor cells; FABER: Flexion, abduction, and external rotation; EANM: The European Association of Nuclear Medicine; MBq: Megabecquerel; mCi: Millicurie; MDP: Methylene diphosphonate; MSCT: Multislice computed tomography; SII: Sacroiliac index; SIJ: Sacroiliac joint

\section{Acknowledgements}

The authors thank Dr. Samar A. Amer, Department of Public Health and Community Medicine, Zagazig University, Egypt, and Mohamed H. Yossif, Kasr El Aini Center of Nuclear Medicine and Oncology, Cairo, Egypt, for their helpful cooperation.

\section{Authors' contributions}

All authors have read and approved the manuscript. Study concept and design were proposed by SA and RA. Patient recruitment, follow-up, and acquisition of data were done by $\mathrm{AE}, \mathrm{SA}$, and HA. Procedures were done by $\mathrm{SA}, \mathrm{HA}$, and RA. Analysis and interpretation of data and drafting of the manuscript were done by RA and HA. Revision of the manuscript was done by $H A, A E$, and SA.

\section{Funding}

No funding was received for this research. 


\section{Availability of data and materials}

The datasets used and/or analyzed during the current study are available from the corresponding author on reasonable request.

\section{Ethics approval and consent to participate}

All procedures performed in studies involving human participants were in accordance with the ethical standards of our institutional research committee of Zagazig University (not applicable) and with the 1964 Helsinki declaration and its later amendments or comparable ethical standards. Informed written consent was obtained from all individual participants included in the study.

\section{Consent for publication}

All patients included in this research gave written informed consent to publish the data contained within this study.

\section{Competing interests}

All authors declared that they had no competing interests.

\section{Author details}

${ }^{1}$ Department of Clinical Oncology and Nuclear Medicine, Faculty of Medicine, Zagazig University, Zagazig, Egypt. 'Department of Rheumatology and Rehabilitation, Faculty of Medicine, Zagazig University, Zagazig, Egypt. ${ }^{3}$ Department of Radiodiagnosis, Faculty of Medicine, Zagazig University, Zagazig, Egypt.

Received: 18 April 2020 Accepted: 26 June 2020

Published online: 08 July 2020

\section{References}

1. Esposito M, Guise T, Kang Y (2018). The biology of bone metastasis. Cold Spring Harbor perspectives in medicine. Jun 1;8(6). https://doi.org/10.1101/ cshperspect.a031252

2. Doddala SM, Suryadevara A, Chinta SK, Madisetty AL (2016) Incidence and pattern of bone metastases at presentation in Indian carcinoma breast patients. Indian J Cancer 53(3):360. https://doi.org/10.4103/0019-509X. 200655

3. Harding D, Giles SL, Brown MRD, Ter Haar GR, an den Bosch Mz, Bartels LW. M. Deppe jj and DeSouza NM (2018). Evaluation of quality of life outcomes following palliative treatment of bone metastases with magnetic resonanceguided high intensity focused ultrasound: an international nulticentre study. Clin Oncol 30. 233-242. https://doi.org/10.1016/j.clon.2017.12.023

4. Thomas L, Balmus C, Ahmadzadehfar H, Essler M, Strunk H, Bundschuh RA (2017) Assessment of bone metastases in patients with prostate cancer-a comparison between 99mTc-bone-scintigraphy and [68Ga]Ga-PSMA PET/CT. Pharmaceuticals (Basel). 10(3):68. https://doi.org/10.3390/ph10030068

5. Bozkurt MF, Kiratli P (2014) Quantitative sacroiliac scintigraphy for pediatric patients: comparison of two methods. Annals of nuclear medicine. 28(3): 227-231. https://doi.org/10.1007/s12149-013-0799-0

6. Sieper J, Braun J, Rudwaleit M, Boonen A, Zink A (2002). Ankylosing spondylitis: an overview. Ann Rheum Dis. 61(suppl 3):iii8-18. https://doi.org/ 10.1136/ard.61.suppl_3.iii8

7. Braun J, Sieper J (2000) Inception cohorts for spondyloarthropathies. Z Rheumatol. 59:117-121. https://doi.org/10.1007/s003930050215

8. Edavalath M (2010) Ankylosing spondylitis. J Ayurveda Integr Med. 1(3):211. https://doi.org/10.4103/0975-9476.72619

9. Van den Wyngaert T, Strobel K, Kampen WU, T. Kuwert T, van der Bruggen W, Mohan HK et al (2016). On behalf of the EANM Bone \& Joint Committee and the Oncology Committee. Eur J Nucl Med Mol Imaging. 43:1723-1738. https://doi.org/10.1007/s00259-016-3415-4

10. Duer A, Ostergaard M, Horslev-Petersen K, Vallo J (2008) Magnetic resonance imaging and bone scintigraphy in the differential diagnosis of unclassified arthritis. Ann Rheum Dis. 67:48-51. https://doi.org/10.1136/ard. 2006.063792

11. Ryan PJ, Gibson T, Fogelman I (1997) Spinal bone SPECT in chronic symptomatic ankylosing spondylitis. Clin Nucl Med. 22:821-824. https://doi. org/10.1097/00003072-199712000-00003

12. Guglielmi G, Cascavilla A, Scalzo G, Salaffi F, Grassi W (2009) Imaging of sternocostoclavicular joint in spondyloarthropathies and other rheumatic conditions. Clin Exp Rheumatol. 27:402-408
13. Koç ZP, Cengiz AK, Aydın F, Samancı N, Yazısız V, Koca SS et al (2015) Sacroiliac indicis increase the specificity of bone scintigraphy in the diagnosis of sacroiliitis. Molecular imaging and radionuclide therapy. 24(1):8. https://doi.org/10.4274/mirt.40427

14. Van der Linden S, Valkenberg HA, Cats A (1984) Evaluation of diagnostic criteria for ankylosing spondylitis. Arthritis Rheum. 27:361-368. https://doi. org/10.1002/art.1780270401

15. Bönisch A, Ehlebracht-König I (2003) The BASDAI-D-an instrument to defining disease status in ankylosing spondylitis and related diseases. Z Rheumatol 62:251-263. https://doi.org/10.1007/s00393-003-0519-6

16. Bagwell JJ, Bauer L, Gradoz M, Terry LG (2016) The reliability of FABER test hip range of motion measurements. Int J Sports Phys Ther 11(7):1101-1101

17. Kacar G, Kacar C, Karayalcin B, Gungor F, Tuncer T, Erkilic M (1998) Quantitative sacroiliac joint scintigraphy in normal subjects and patients with sacroiliitis, Ann Nucl Med. 12:169-173. https://doi.org/10.1007/ BF03164785

18. Tiwari BP, Basu S (2013) Estimation of sacroiliac joint index in normal subjects of various age groups: comparative evaluation of four different methods of quantification in skeletal scintigraphy. Nuclear Medicine Review. 16(1):26-30. https://doi.org/10.5603/NMR.2013.0005

19. Vyas K, Eklem M, Seto H, Bobba VR, Brown P, Haines J et al (1981) Quantitative scintigraphy of sacroiliac joints: effects of age, gender, and laterality. American Journal of Roentgenology. 136(3):589-592. https://doi. org/10.2214/ajr.136.3.589

20. Davis P (1979) Quantitative sacroiliac scintigraphy in ankylosing spondylitis and Crohn's disease: a single family study. Annals of the Rheumatic Diseases. 38:241-243. https://doi.org/10.1136/ard.38.3.241

21. Özdoğan Ö, Değirmenci B, Şenocak Ö, Gülbahar S, Arslan G, Taşçı C, Akalın E, Durak H (2011) Tc-99 m HIG scintigraphy in detection of active inflammation in ankylosing spondylitis. Mol Imaging Radionucl Ther 20(2): 52. https://doi.org/10.4274/MIRT.21

22. Kim Yl, Suh M, Kim YK, Lee HY, Shin K (2015) The usefulness of bone SPECT/ $\mathrm{CT}$ imaging with volume of interest analysis in early axial spondyloarthritis. BMC musculoskeletal disorders.16(1):9. https://doi.org/10.1186/s12891-0150465-x

\section{Publisher's Note}

Springer Nature remains neutral with regard to jurisdictional claims in published maps and institutional affiliations.

\section{Submit your manuscript to a SpringerOpen ${ }^{\circ}$ journal and benefit from:}

- Convenient online submission

- Rigorous peer review

- Open access: articles freely available online

High visibility within the field

- Retaining the copyright to your article

Submit your next manuscript at $\boldsymbol{\nabla}$ springeropen.com 